Check for updates

Cite this: Org. Biomol. Chem., 2020, 18, 2817

Received 4th March 2020,

Accepted 24th March 2020

DOI: $10.1039 / \mathrm{d} 0 o b 00468 \mathrm{e}$

rsc.li/obc

\section{Merging singlet-oxygen induced furan oxidations with organocatalysis: synthesis of enantiopure cyclopentanones and hydrindanes $\uparrow$}

\author{
Dimitris Kalaitzakis, (id Manolis Sofiadis, Vasileios Tsopanakis, Tamsyn Montagnon \\ and Georgios Vassilikogiannakis (D)*
}

\begin{abstract}
A new methodology is described herein which converts simple and readily accesible furan substrates into complex enantio-enriched carbocyclic skeletons through the implementation of a simple one-pot procedure. Singlet oxygen furan photoxygenation affords an enedione which then participates in an organocatalysed double-Michael reaction with an enal to furnish a cyclopentanone structure with up to four new contiguous stereogenic centres. The enantioselectivity and diastereoselectivity of this process are both excellent. If desired, further aldol-annulation steps can be appended to the cascade reaction sequence to afford key enantiopure hydrindane motifs.
\end{abstract}

\section{Introduction}

Sustainability in chemistry ${ }^{1}$ is a complex paradigm that is in reality very difficult to achieve because it encompasses so many seemingly disparate facets. From using benign ${ }^{2}$ and abundant reagents and feedstocks ${ }^{3}$ to both atom- ${ }^{4}$ and stepeconomy ${ }^{5}$ (concepts united in "ideal" chemistry $^{6}$ ), a host of different reaction characteristics affect its overall measurement. ${ }^{7}$ In our work, we have made substantial progress towards achieving the goal by using the traceless oxidant singlet oxygen, ${ }^{1} \mathrm{O}_{2}$, to orchestrate cascade sequences which turn simple, readily accessible and relatively "flat" molecules into complex three-dimensional target scaffolds over the course of one synthetic operation. ${ }^{8}$ During this research, we have managed to solve a number of problems and meet additional challenges, such as using water as a solvent, ${ }^{9}$ applying the new methodologies within fragile biological molecules $^{8 e}$ or scaling-up our photochemical processes. ${ }^{10}$ However, one fundamental pillar remained that, unless incorporated into the strategy, would limit its utility because of the homo-

Department of Chemistry, University of Crete, Vasilika Vouton, 71003 Iraklion, Crete, Greece.E-mail:vasil@uoc.gr

$\dagger$ Electronic supplementary information (ESI) available. See DOI: 10.1039/ d0ob00468e chiral world we live in: we needed to turn these racemic synthetic technologies into enantioselective ones. By combining the enantioselective bond forming power of organocatalysis, ${ }^{11}$ which often also scores high in sustainability metrics, with such cascades, ${ }^{12}$ we have now achieved a big step forward towards meeting this fundamental challenge.

Singlet oxygen reactions have been paired with organocatalysis in the past in single step, simple, functional group interconversions $;{ }^{13-15}$ more specifically, stereoselective $\alpha$-hydroxylation of ketones, ${ }^{13}$ aldehydes ${ }^{14}$ and 1,3-dicarbonyl compounds. ${ }^{15}$ The only multistep procedures are still a form of enantioselective hydroxylation, but in this case they proceed via a Kornblum-DeLaMare rearrangement (diene $\rightarrow$ 4-hydroxy2-enone). ${ }^{16}$ We are targeting something different, a more general framework building reaction cascade wherein multiple bonds are diastereo- and enantioselectively constructed in a single synthetic operation.

Recently, we achieved the syntheses of a number of fused $\mathrm{N}$-containing [5,5]-bicycles ${ }^{12}$ via organocatalysed reactions of 4-pyrrolin-2-ones, ${ }^{17}$ but we now wanted to target some allcarbon skeletons with greater ubiquity and value, namely, enantiopure cyclopentanones, as well as important fused bicyclic congeners, and we hoped to do this by commandeering the enedione (of type 1i, Scheme 1) produced upon photooxygenation of furan substrates. Enediones should be extremely versatile due to their multisite and multi-type reactivity; features that lend themselves to their participation in domino reactions and/or complexity building sequences. ${ }^{8 a, 17}$ However, they have not been used as frequently as one might expect, ${ }^{18}$ given these desirable characteristics because of two intrinsically linked properties of theirs: firstly, there are few general syntheses of these intermediates, ${ }^{8}$ and, secondly, they are relatively unstable, which makes their storage and handling more complicated than it would otherwise be. In addition, tunability - the ability to control the site and type of reaction - has not yet been broadly achieved. ${ }^{19}$ In contrast, 4-oxo-alkyl-2-enoates (keto-ene-ester/acid) and amido-ene-keto/ester/acid have been widely studied due to their enhanced stability and more pre- 


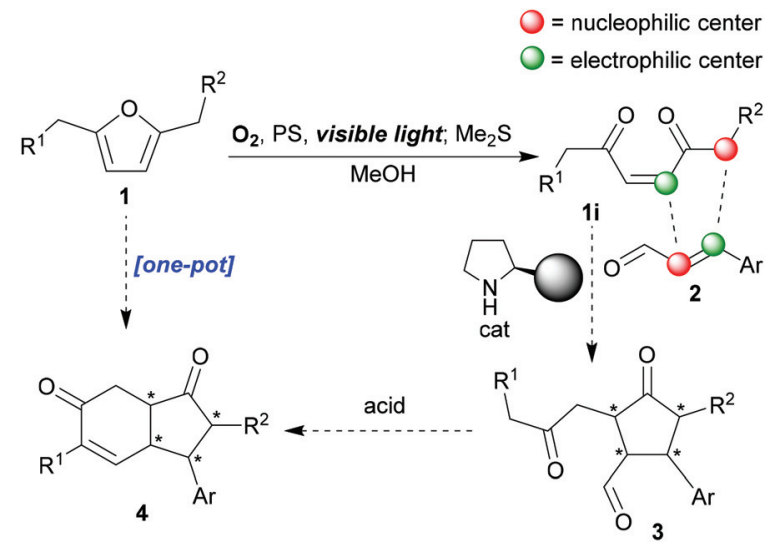

Scheme 1 Proposed synthetic strategy for enantioselective access to cyclopentanones and hydrindane scaffolds.

dictable reactivity patterns. ${ }^{20,21}$ We knew that we could make a wide variety of enediones in situ through mild furan photoxygenation protocols ${ }^{8}(\mathbf{1} \rightarrow \mathbf{1 i}$, Scheme 1$)$, thus, overcoming the problems described earlier. Crucially, furans, with a full range of substitution patterns, are readily accessible ${ }^{22}$ (including from biomass ${ }^{3}$ ). So we hoped that we could now build into our singlet-oxygen initiated cascade reaction sequences subsequent organo-catalysed double-Michael reactions $(\mathbf{1 i}+\mathbf{2} \rightarrow$ 3, Scheme 1) that would furnish the desired cyclopentanones; regioselectively, diastereoselectively and enantioselectively. The efficient and stereoselective synthesis of cyclopentanes and cyclopentanones continues to be a very important challenge. ${ }^{23}$ If this initial target, creating up to four new contiguous stereocenters controllably, was successfully attained, we then hoped to extend the sequence to encompass an aldol-annulation $(\mathbf{3} \rightarrow \mathbf{4}$, reminiscent of the Hajos-Parrish-Eder-SauerWiechert reaction ${ }^{24}$ ), thus, also giving us stereoselective access to key hydrindane motifs ${ }^{24,25}(\mathbf{4}$, Scheme 1$)$. Hydrindanes are core units of a large number of structurally diverse natural product targets.

\section{Results and discussion}

We chose to start our investigation using the commercially available Jørgensen-Hayashi catalyst $^{26}$ which had already proved so successful in many iminium catalysis scenarios (including hydrindane synthesis ${ }^{25}$ ). cis-Enedione 1ai was synthesised from furan 1a using the standard photoxygenation protocol that we had developed previously; ${ }^{8 d-m}$ we then tested its reaction with enal $2 \mathrm{a}$ under a range of conditions (Scheme 2). With regard to solvents, protic solvents proved to be the most efficient. Moreover, we were gratified to find that the "green" EtOH : $\mathrm{H}_{2} \mathrm{O}$ mixture proved to be the best system tested (EtOH being a green solvent with attractive properties ${ }^{27}$ ). The enantiomeric and diastereomeric excesses obtained in these initial experiments were impressive. Furthermore, it was revealed that both geometrical isomers 1ai and 1aii gave the same product. When pure enedione 1ai was subjected to the
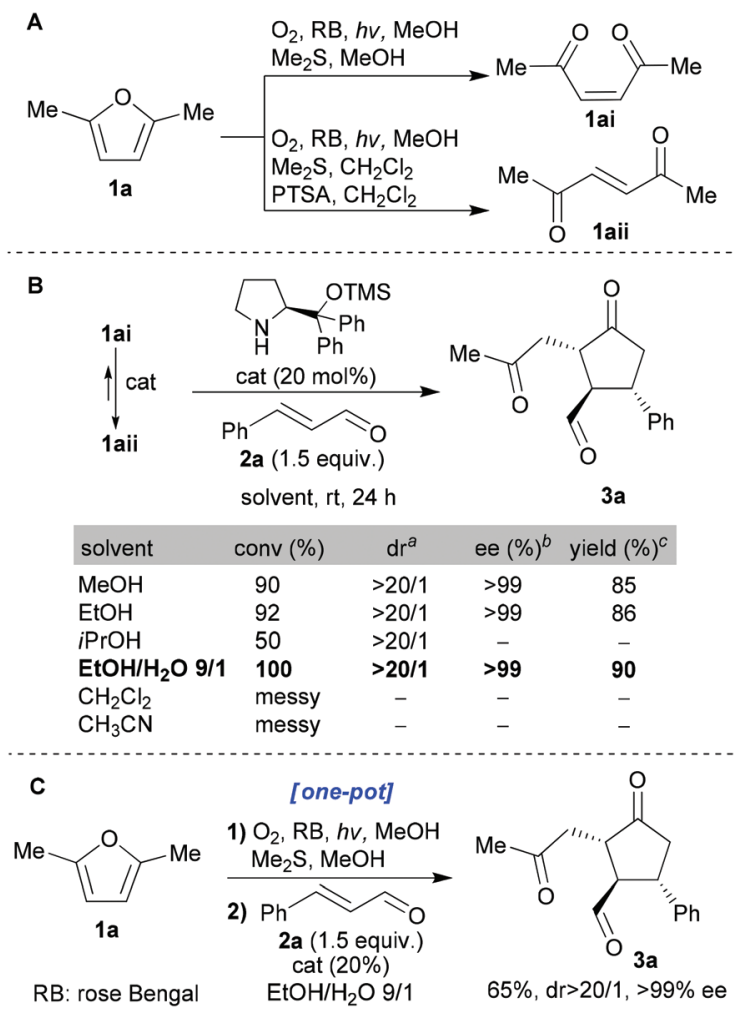

Scheme 2 A) Singlet oxygen triggered transformation of 1a into the enediones 1ai and 1aii. (B) Optimization of the organocatalytic conditions. ${ }^{a}$ Determined by ${ }^{1} \mathrm{H}-\mathrm{NMR}$ of the crude reaction mixture. ${ }^{b}$ Determined by chiral HPLC analysis after reduction of the aldehyde group of 3a (isolated) using $\mathrm{NaBH}_{4} .{ }^{C}$ Yields of isolated $3 a$. (C) One-pot transformation of furan $1 \mathrm{a}$ to enantio-enriched $3 \mathrm{a}$. All reactions were performed on a $0.1 \mathrm{mmol}$ scale.

organocatalyst $(20 \mathrm{~mol} \%)$ in EtOH $: \mathrm{H}_{2} \mathrm{O} \quad(9: 1)$, after 30 minutes complete isomerisation (cis $\rightarrow$ trans) had occurred. Exactly the same isomerisation was observed under the reaction conditions within 30 minutes. Finally, the optimized conditions were applied to a one-pot protocol starting directly from furan 1a which impressively afforded 3a in 65\% overall isolated yield (with excellent dr and ee, Scheme 2C).

These conditions were then applied to various enals (Scheme 3). All the ee values were measured using chiral HPLC analysis after reduction of the aldehyde group using $\mathrm{NaBH}_{4}$ (see the $\mathrm{ESI} \dagger$ for full details). It can be seen that the dr and ee values were consistently extremely high and that isolated yields were excellent (59-65\% for the one-pot processes and $79-95 \%$ for the stepwise variant) given the degree to which the complexity was enhanced through this one-pot process. Finally, the use of aliphatic enal 2-hexenal led to a messy reaction mixture containing a small amount of the desired cyclopentanone.

We next turned our attention to extending the reaction sequence by adding an aldol-annulation step. To this end, isolated cyclopentanones $3 \mathbf{a}, 3 \mathbf{c}$, and $3 \mathbf{e}$ were heated $\left(70{ }^{\circ} \mathrm{C}\right)$ in DCE with PTSA (0.7 equiv.) for 8 hours (Scheme 4A). These conditions gave the desired fused products $\mathbf{4 a}, \mathbf{4 c}$ and $\mathbf{4 e}$ with 

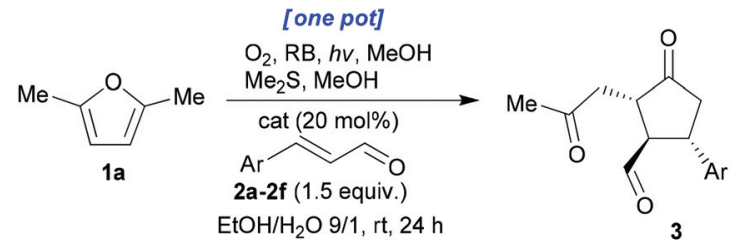

$\begin{array}{lccc}\quad \text { product 3 } & \mathrm{dr}^{a} & \text { ee }(\%)^{b} & \text { yield }(\%) \\ \text { 3a: } \mathrm{Ar}=\mathrm{Ph} & >20 / 1 & >99 & 65(90) \\ \text { 3b: } \mathrm{Ar}=4-\mathrm{MeO}-\mathrm{C}_{6} \mathrm{H}_{4} & >20 / 1 & 98 & 60(84) \\ \text { 3c: } \mathrm{Ar}=4-\mathrm{Cl}-\mathrm{C}_{6} \mathrm{H}_{4} & >20 / 1 & >99 & 59(79) \\ \text { 3d: } \mathrm{Ar}=4-\mathrm{Et}_{-} \mathrm{C}_{6} \mathrm{H}_{4} & >20 / 1 & >99 & 62(88) \\ \text { 3e: } \mathrm{Ar}=2-\mathrm{MeO}-\mathrm{C}_{6} \mathrm{H}_{4} & >20 / 1 & >99 & 63(95) \\ \text { 3f: } \mathrm{Ar}=2-\mathrm{F}-\mathrm{C}_{6} \mathrm{H}_{4} & >20 / 1 & >99 & 65(90)\end{array}$

Scheme 3 One-pot synthesis of optically pure cyclopentanones of type 3 from furan 1a. All reactions were performed on a $0.1 \mathrm{mmol}$ scale. ${ }^{a}$ Determined by ${ }^{1} \mathrm{H}-\mathrm{NMR}$ of the crude reaction mixture. ${ }^{b}$ Determined by chiral HPLC analysis after reduction of the aldehyde group of the isolated 3 using $\mathrm{NaBH}_{4} .{ }^{c}$ Yields of isolated products 3 . In parentheses are the isolated yields of products 3 when the reaction started from pure 1ai.

A
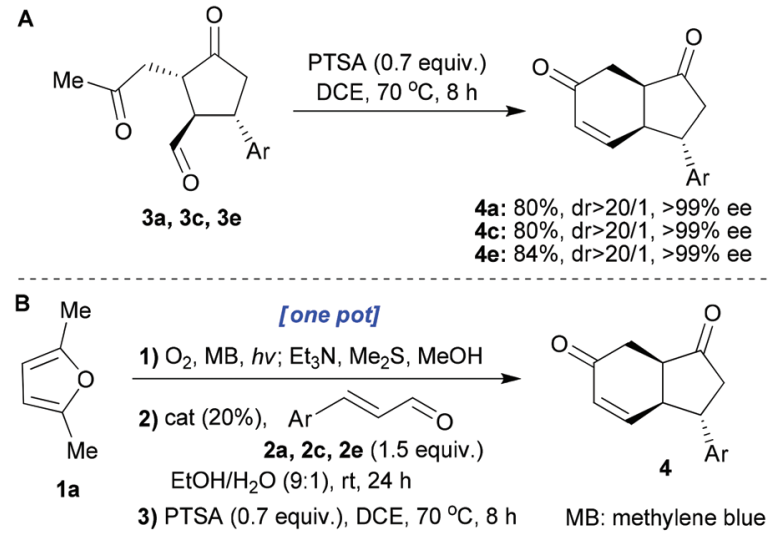
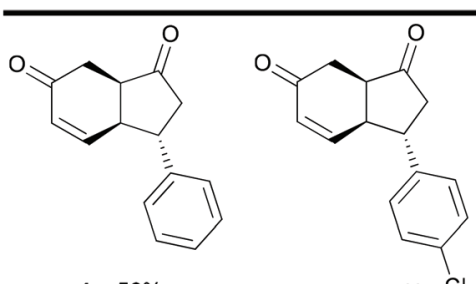

$4 c: 53 \%, C l$
$d r>20 / 1,>99 \%$ ee

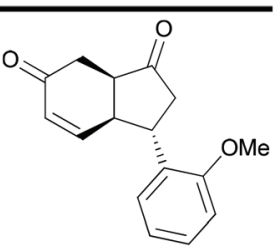

4a: $58 \%$ $4 a: 58 \%$
$d r>20 / 1,>99 \%$ ee
$4 \mathrm{e}: 55 \%$ $d r>20 / 1,>99 \%$ ee
Scheme 4 A) Synthesis of hydrindanes 4 starting from cyclopentanones 3. (B) One-pot synthesis of hydrindanes 4 starting from furan 1 a. All the reactions were performed on a $0.1 \mathrm{mmol}$ scale. The yields refer to isolated compounds. The $\mathrm{dr}$ values were measured by ${ }^{1} \mathrm{H}-\mathrm{NMR}$ of the crude reaction mixture. The ee values were determined by chiral HPLC analysis.

excellent yields, $\mathrm{dr}$ and ee (80-84, $>20 / 1$ and $>99 \%$, respectively). cis-Hydrindanes $\mathbf{4 a}, \mathbf{4 c}$ and $\mathbf{4 e}$ were formed despite the starting aldehydes having a trans relationship at the corresponding centres (easily explained by the epimerisability of the centre next to the ketone when heated in the presence of an acid). This reaction was then successfully transferred into the one-pot protocol $(\mathbf{1 a} \rightarrow \mathbf{4 a}, \mathbf{4 c}, \mathbf{4 e}$; Scheme $4 \mathrm{~B})$. When the final aldol/dehydration step is included in our one-pot sequences, without isolation and purification of the intermediates, we observed that isolated yields of the final products were a bit better when methylene blue was used instead of rose Bengal. For this reason, we decided to use methylene blue in these one-pot protocols.

In the next part of our study, unsymmetrical furans were investigated. In this case, while stereoselectivity remained paramount, good regioselectivity in the organo-catalysed step also needed to be attained. Enedione $\mathbf{1 b i}$ was prepared and shown to exhibit identical behaviour to enedione 1ai in terms of its cis $\rightarrow$ trans isomerisation (in $\mathrm{EtOH}: \mathrm{H}_{2} \mathrm{O} 9: 1$, complete in $30 \mathrm{~min}$ ) catalysed by the organocatalyst (20 $\mathrm{mol} \%$, Scheme 5). The previously optimised protocol (shown in Schemes 2 and 3) was, therefore, applied to furan $\mathbf{1 b}$ with notable results (entry 1 of the table shown in Scheme 5). The major product was $\mathbf{5 a}\left(\mathbf{5 a} / \mathbf{5} \mathbf{a}^{\prime}=3 / 1\right.$, yield $52 \%$, for isolated $\left.\mathbf{5 a}\right)$ wherein the position $\alpha$ to a ketone that was more substituted (1bii, the position shown in red, Scheme 5) had reacted preferentially over the less substituted one (1bii, shown in orange, Scheme 5). Moreover, we managed to improve the regioselectivity by further promoting the formation of the product that comes from the thermodynamic enolate (increasing the

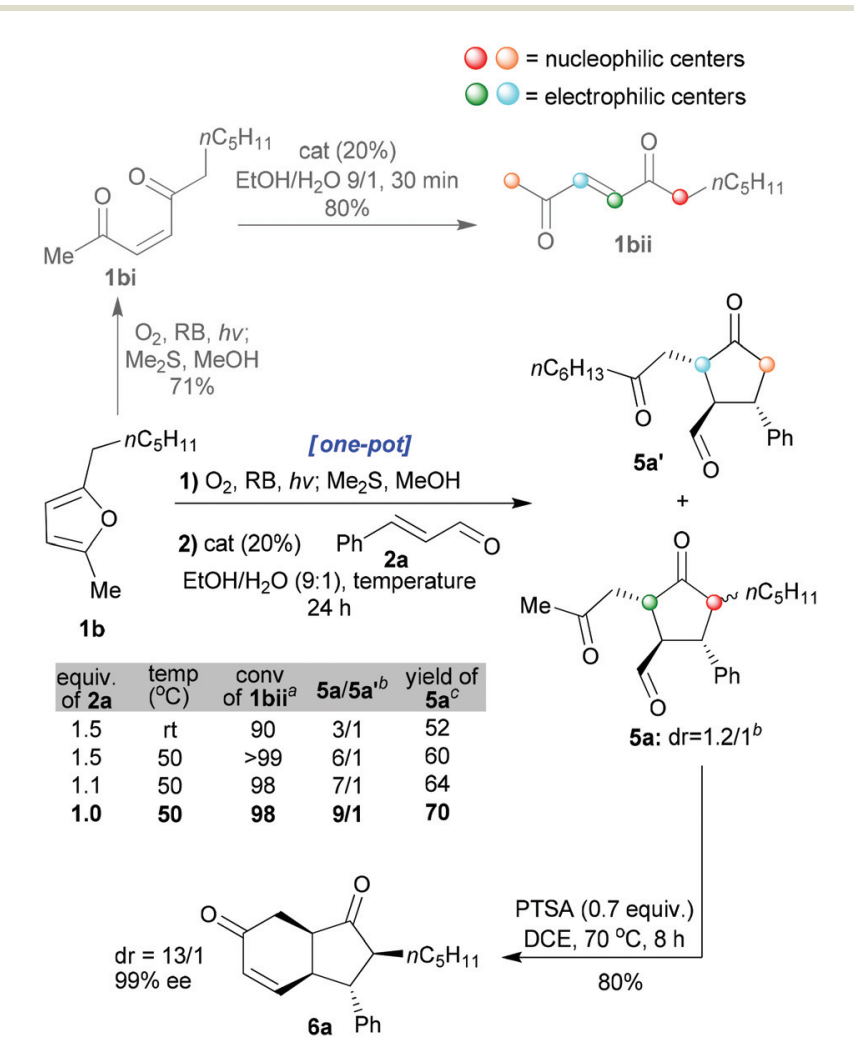

Scheme 5 Studies on the stereoselective \& regioselective one-pot transformation of $1 \mathrm{~b}$ into cyclopentanones $5 \mathrm{a}$ and $5 \mathrm{a}^{\prime}$ and subsequent conversion to the carbocycle $6 \mathrm{a} .{ }^{\alpha}$ Conversion refers to the transformation of intermediate $1 \mathrm{bii}$ to $5 \mathrm{a}$ and $5 \mathrm{a}^{\prime}$ and was determined by ${ }^{1} \mathrm{H}-\mathrm{NMR}$ of the crude reaction mixture. ${ }^{b}$ Determined by ${ }^{1} \mathrm{H}-\mathrm{NMR}$ of the crude reaction mixture. ${ }^{c}$ Isolated yields of the inseparable diastereomers of product $5 \mathrm{a}$ from furan $\mathbf{1 b}$. 
temperature and decreasing the equivalence of enal 2a employed, entries 2-4 in the table within Scheme 5). In this way a ratio of $9 / 1$ could be obtained for $5 \mathbf{a} / \mathbf{5} \mathbf{a}^{\prime}$ and the product 5a could be formed as a 1.2/1 mixture of inseparable diastereoisomers (isolated yield of $70 \%$ from $\mathbf{1 b}$ ). In a further mechanistic clarification, the minor isomer $\mathbf{5} \mathbf{a}^{\prime}$ was isolated, dissolved in $\mathrm{EtOH} / \mathrm{H}_{2} \mathrm{O}(9 / 1,0.1 \mathrm{M})$ and an organocatalyst (20 mol\%) was added. The resulting solution was heated to $50{ }^{\circ} \mathrm{C}$ and stirred for $24 \mathrm{~h}$. No formation of isomer $5 \mathbf{a}$ was seen, confirming that the cyclisation is not reversible.

Interestingly, the cyclisation reaction of 5a led exclusively to cis-fused 6a with a high distereomeric ratio and excellent enantiomeric excess (dr: 13/1, ee: 99\%, and isolated yield: $80 \%$ ). In this case, two epimerisations had occurred (both sides of the ketone, red and green positions 5a, Scheme 5). The optimised individual steps were then combined in one-pot reaction sequences beginning from a variety of disubstituted furans and employing a variety of enals $(\mathbf{1}+\mathbf{2} \rightarrow \mathbf{6}$, Scheme 6$)$. The results, presented in Scheme 6 , show that all the reactions afforded the desired products bearing 4 new stereogenic centres in good yields and with high dr and ee values.

In the final stage of the investigation, and to ensure that the new method could be applied to a wider range of synthetic challenges, we transposed the process into a continuous flow photoreactor ${ }^{28}$ to facilitate larger scale synthesis of these compounds. The photoreactor we used is our prototype ${ }^{10}$ based on the principle of irradiating nebulised mixtures. Use of the nebula overcomes issues of poor light penetration (rapid light attenuation, Bouger-Lambert-Beer law) and maximising gas-
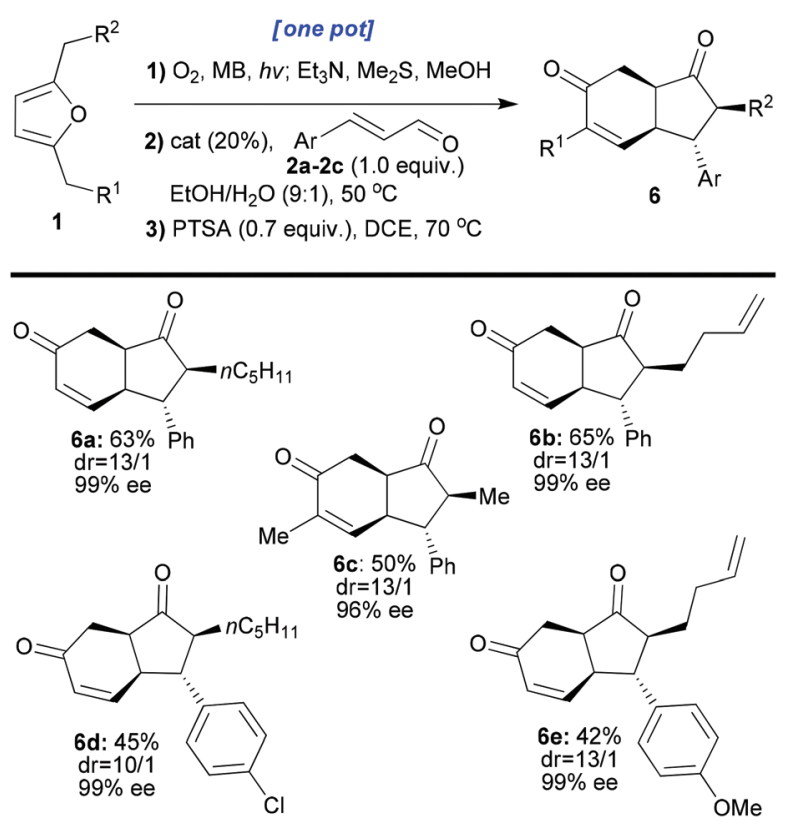

Scheme 6 One-pot synthesis of enantio-enriched carbocycles of type 6 from disubstituted furans of type 1. All the reactions were performed on a $0.1 \mathrm{mmol}$ scale. The yields refer to the isolated compounds. The $\mathrm{dr}$ values were measured by ${ }^{1} \mathrm{H}-\mathrm{NMR}$ of the crude reaction mixture. The ee values were determined by chiral HPLC analysis.

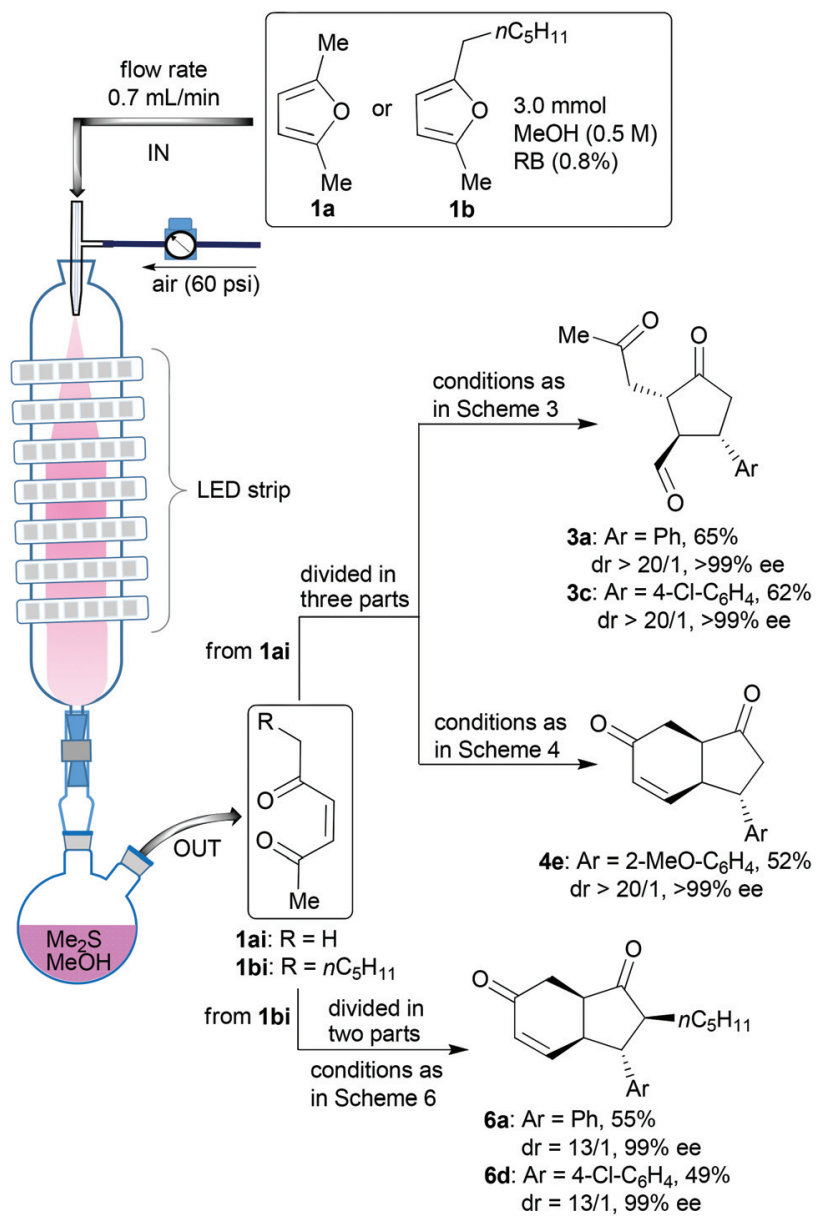

Scheme 7 Use of a prototype photoreactor to achieve larger scale reaction sequences.

liquid interfaces for these biphasic reactions which have hindered the development of photochemical continuous flow reactor technologies. A series of test reactions were run in this system starting from either furan $\mathbf{1 a}$ or $\mathbf{1 b}$ (Scheme 7). In each case, after the photoxygenation step in the photoreactor (conversion $=100 \%$ and productivity $=0.35 \mathrm{mmol} \mathrm{min}^{-1}$ ), the oxidation products were collected in two flasks precharged with methanol and dimethylsulfide to achieve immediate reduction of the intermediate hydroperoxides to the enediones 1ai and 1bi. The solutions were divided and treated under different conditions (adapted from those described in Schemes 3, 4 and 6) to afford a range of products on a larger scale (1ai $\rightarrow \mathbf{3 a}, \mathbf{3 c}$ or $\mathbf{4 e}$ and $\mathbf{1} \mathbf{b i} \rightarrow \mathbf{6 a}$ or $\mathbf{6 d}$ ) with the expected (high) selectivities.

\section{Conclusions}

Herein, we have presented a general, flexible and highly effective method for the regio-, diastereo- and enantioselective synthesis of important carbocycles, namely, enantiopure cyclopentanones and their hydrindane congeners. The protocols 
developed are all one-pot protocols which involve the use of relatively "flat" furan substrates and controllably transform them into three-dimensionally complex scaffolds with very high levels of stereochemical purity. The method exploits the ready accessibility of furans, variously substituted at will, as well as, their highly sustainable photoxygenation which affords a full range of reactive enedione intermediates ready for further reaction. The newly developed technology has also been successfully scaled-up using a prototype continuous flow photoreactor to further enhance the broad synthetic utility of this chemistry.

\section{Conflicts of interest}

There are no conflicts to declare.

\section{Acknowledgements}

We would like to dedicate this article to Prof. John Gallos, our mentor and friend, on the occasion of his retirement.

The research leading to these results has received funding from the European Research Council under the European Union's Seventh Framework Programme (FP7/2007-2013)/ERC grant agreement no. 277588. We thank the Greek General Secretariat of Research and Technology for matching (reward) funds (KA: 4143). We also thank the Alexander S. Onassis Public Benefit Foundation for the Ph.D. fellowship of Manolis Sofiadis (G ZM 063-1/2016-2017).

\section{Notes and references}

1 (a) For the 12 principles of Green Chemistry, see: P. T. Anastas and J. C. Warner, Green Chemistry: Theory and Practice, Oxford University Press, New York, 1998; (b) C.-J. Li and B. M. Trost, Proc. Natl. Acad. Sci. U. S. A., 2008, 105, 13197.

2 Benign can be defined (see ref that follows) as "a byproduct, reagent or solvent that has no known environmental risk associated with it; for example water, low-concentration saline, dilute ethanol, autoclaved cell mass, etc.”. T. Hudlicky, D. A. Frey, L. Koroniak, C. D. Claeboe and L. E. Brammer Jr., Green Chem., 1999, 1, 57.

3 D. Sengupta and R. W. Pike, Chemicals from Biomass; Integrating Bioprocesses into Chemical Production Complexes for Sustainable Development, CRC Press, Boca Raton Florida, 2012.

4 B. A. Trost, Science, 1991, 254, 1471.

5 P. A. Wender and B. L. Miller, Nature, 2009, 460, 197.

6 (a) T. Newhouse, P. S. Baran and R. W. Hoffmann, Chem. Soc. Rev., 2009, 38, 3010; (b) T. Gaich and P. S. Baran, J. Org. Chem., 2010, 75, 4657.

7 For a discussion on metrics, see: A. Lapkin and D. J. C. Constable, Green Chemistry Metrics: Measuring and Monitoring Sustainable Processes, Wiley, UK, 2008.
8 For reviews, see: (a) T. Montagnon, D. Kalaitzakis, M. Triantafyllakis, M. Stratakis and G. Vassilikogiannakis, Chem. Commun., 2014, 50, 15480; (b) T. Montagnon, D. Noutsias, I. Alexopoulou, M. Tofi and G. Vassilikogiannakis, Org. Biomol. Chem., 2011, 9, 2031; (c) T. Montagnon, M. Tofi and G. Vassilikogiannakis, Acc. Chem. Res., 2008, 41, 1001. For leading examples, see: (d) D. Kalaitzakis, M. Triantafyllakis, G. I. Ioannou and G. Vassilikogiannakis, Angew. Chem., Int. Ed., 2017, 56, 4020; (e) E. Antonatou, K. Hoogewijs, D. Kalaitzakis, A. Baudot, G. Vassilikogiannakis and A. Madder, Chem. Eur. J., 2016, 22, 8457; (f) D. Kalaitzakis, M. Triantafyllakis, M. Sofiadis, D. Noutsias and G. Vassilikogiannakis, Angew. Chem., Int. Ed., 2016, 55, 4605; $(g)$ D. Kalaitzakis, D. Noutsias and G. Vassilikogiannakis, Org. Lett., 2015, 17, 3596; (h) D. Kalaitzakis, A. Kouridaki, D. Noutsias, T. Montagnon and G. Vassilikogiannakis, Angew. Chem., Int. Ed., 2015, 54, 6283; (i) D. Kalaitzakis, T. Montagnon, E. Antonatou, N. Bardají and G. Vassilikogiannakis, Chem. - Eur. J., 2013, 19, 10119; (j) D. Kalaitzakis, T. Montagnon, I. Alexopoulou and G. Vassilikogiannakis, Angew. Chem., Int. Ed., 2012, 51, 8868; (k) I. Margaros, T. Montagnon and G. Vassilikogiannakis, Org. Lett., 2007, 9, 5585; (l) T. Georgiou, M. Tofi, T. Montagnon and G. Vassilikogiannakis, Org. Lett., 2006, 8, 1945; (m) G. Vassilikogiannakis and M. Stratakis, Angew. Chem., Int. Ed., 2003, 42, 5465.

9 (a) D. Kalaitzakis, M. Triantafyllakis, I. Alexopoulou, M. Sofiadis and G. Vassilikogiannakis, Angew. Chem., Int. Ed., 2014, 53, 13201; (b) D. Noutsias, I. Alexopoulou, T. Montagnon and G. Vassilikogiannakis, Green Chem., 2012, 14, 601; (c) A. Kouridaki, T. Montagnon, M. Tofi and G. Vassilikogiannakis, Org. Lett., 2012, 14, 2374.

10 (a) G. I. Ioannou, T. Montagnon, D. Kalaitzakis, S. A. Pergantis and G. Vassilikogiannakis, ChemPhotoChem, 2018, 2, 860; (b) G. I. Ioannou, T. Montagnon, D. Kalaitzakis, S. A. Pergantis and G. Vassilikogiannakis, Org. Biomol. Chem., 2017, 15, 10151; (c) G. I. Ioannou, T. Montagnon, D. Kalaitzakis, S. A. Pergantis and G. Vassilikogiannakis, ChemPhotoChem, 2017, 1, 173.

11 (a) S. Bertelsen and K. A. Jørgensen, Chem. Soc. Rev., 2009, 38, 2178; (b) D. W. C. MacMillan, Nature, 2008, 455, 304; (c) C. F. Barbas, Angew. Chem., Int. Ed., 2008, 47, 42.

12 D. Kalaitzakis, M. Sofiadis, M. Triantafyllakis, K. Daskalakis and G. Vassilikogiannakis, Org. Lett., 2018, 20, 1146.

13 H. Sundén, M. Engqvist, J. Casas, I. Ibrahem and A. Córdova, Angew. Chem., Int. Ed., 2004, 43, 6532.

14 (a) A. Córdova, H. Sundén, M. Engqvist, I. Ibrahem and J. Casas, J. Am. Chem. Soc., 2004, 126, 8914; (b) I. Ibrahem, G. L. Zhao, H. Sundén and A. Córdova, Tetrahedron Lett., 2006, 47, 4659; (c) D. J. Walaszek, K. Rybicka-Jasińska, S. Smoleń, M. Karczewski and D. Gryko, Adv. Synth. Catal., 2015, 357, 2061.

15 (a) X. F. Tang, J. N. Zhao, Y. F. Wu, Z. H. Zheng, S. H. Feng, Z. Y. Yu, G. Z. Liu and Q. W. Meng, Org. Biomol. Chem., 
2019, 17, 7938; (b) Y. Wang, H. Yin, X. Tang, Y. Wu, Q. Meng and Z. Gao, J. Org. Chem., 2016, 81, 7042; (c) M. Lian, Z. Li, Y. Cai, Q. Meng and Z. Gao, Chem. Asian J., 2012, 7, 2019.

16 (a) C. Wiegand, E. Herdtweck and T. Bach, Chem. Commun., 2012, 48, 10195; (b) S. T. Staben, X. Linghu and F. D. Toste, J. Am. Chem. Soc., 2006, 128, 12658.

17 T. Montagnon, D. Kalaitzakis, M. Sofiadis and G. Vassilikogiannakis, Org. Biomol. Chem., 2020, 18, 180.

18 For examples of enedione use in asymmetric organocatalysis, see: (a) D. Trubitsõn, S. Žari, S. Kaabel, M. Kudrjashova, K. Kriis, I. Järving, T. Pehk and T. Kanger, Synthesis, 2018, 50, 314; (b) B. Zhu, S. Qiu, J. Li, M. L. Coote, R. Lee and Z. Jiang, Chem. Sci., 2016, 7, 6060; (c) M. Ošeka, A. Noole, S. Žari, M. Öeren, I. Järving, M. Lopp and T. Kanger, Eur. J. Org. Chem., 2014, 3599. For examples of the closely related keto-ene-CHO, see: (d) Y. Hayashi, K. Nagai and S. Umemiya, Chem. - Asian J., 2019, 14, 4146; (e) B. M. Paz, L. Klier, L. Næsborg, V. H. Lauridsen, F. Jensen and K. A. Jørgensen, Chem. Eur. J., 2016, 22, 16810; $(f)$ M. He, J. R. Struble and J. W. Bode, J. Am. Chem. Soc., 2006, 128, 8418.

19 In our own chemistry, pendent nucleophiles have frequently been used to control regioselectivity; for examples, see ref. $8 a-c$.

20 For keto-ene-ester/acid examples, see: (a) J.-B. Lin, S.-M. Xu, J.-K. Xie, H.-Y. Li and P.-F. Xu, Chem. Commun., 2015, 51, 3596; (b) W. Zhou, X. Su, M. Tao, C. Zhu, Q. Zhao and J. Zhang, Angew. Chem., Int. Ed., 2015, 54, 14853; (c) S. Žari, M. Kudrjashova, T. Pehk, M. Lopp and T. Kanger, Org. Lett., 2014, 16, 1740. For amide-ene ${ }_{n}$-keto/ ester/acid $(n=1,2)$ examples, see: $(d)$ S. Muthusamy and V. Kesavan, Eur. J. Org. Chem., 2019, 4046; (e) B.-X. Xiao, W. Du and Y.-C. Chen, Adv. Synth. Catal., 2017, 359, 1018; (f) K. S. Halskov, F. Kniep, V. H. Lauridsen, E. H. Iversen, B. S. Donslund and K. A. Jørgensen, J. Am. Chem. Soc., 2015, 137, 1685; $(g)$ J. Stiller, P. H. Poulsen, D. C. Cruz, J. Dourado, R. L. Davis and K. A. Jørgensen, Chem. Sci., 2014, 5, 2052; (h) L. Hong and R. Wang, Adv. Synth. Catal., 2013, 355, 1023; (i) K. Jiang, Z.-J. Jia, X. Yin, L. Wu and Y.-C. Chen, Org. Lett., 2010, 12, 2766.

21 Very recently a paper describing the formal $[3+2]$-cycloaddition between (E)-ethyl 4-oxopent-2-enoate and 2-enals for an elegant synthesis of Corey's lactone has been published, see: N. Umekubo, Y. Suga and Y. Hayashi, Chem. Sci., 2020, 11, 1205.

22 (a) A. Deepthi, B. P. Babu and A. L. Balachandran, Org. Prep. Proced. Int., 2019, 51, 409; (b) A. Blanc, V. Bénéteau, J. M. Weibel and P. Pale, Org. Biomol. Chem., 2016, 14, 9184; (c) A. V. Gulevich, A. S. Dudnik, N. Chernyak and V. Gevorgyan, Chem. Rev., 2013, 113, 3084; (d) X. L. Hou, H. Y. Cheung, T. Y. Hon, P. L. Kwan, T. H. Lo, S. Y. Tong and H. N. C. Wong, Tetrahedron, 1998, 54, 1955.

23 For a review of chiral cyclopentenone syntheses, see: (a) S. P. Simeonov, J. P. M. Nunes, K. Guerra, V. B. Kurteva and C. A. M. Afonso, Chem. Rev., 2016, 116, 5744. For selected examples of organocatalysed cyclopentanone synthesis, see: (b) K. E. Ozboya and T. Rovis, Chem. Sci., 2011, 2, 1835; (c) A. Ma and D. Ma, Org. Lett., 2010, 12, 3634. For selected examples of stereoselective organocatalysed cyclopentane synthesis with $\geq 3$ centres controlled, see: (d) M. Laugeois, S. Ponra, V. Ratovelomanana-Vidal, V. Michelet and M. R. Vitale, Chem. Commun., 2016, 52, 5332; (e) K. S. Halskov, L. Næsborg, F. Tur and K. A. Jørgensen, Org. Lett., 2016, 18, 2220; (f) B.-C. Hong, N. S. Dange, C.-S. Hsu, J.-H. Liao and G.-H. Lee, Org. Lett., 2011, 13, 1338; $(g)$ P. V. Pham, K. Ashton and D. W. C. MacMillan, Chem. Sci., 2011, 2, 1470; (h) G.-L. Zhao, I. Ibrahem, P. Dziedzic, J. Sun, C. Bonneau and A. Córdova, Chem. - Eur. J., 2008, 14, 10007; (i) B. Tan, Z. Shi, P. J. Chua and G. Zhong, Org. Lett., 2008, 10, 3425; (j) D. Enders, C. Wang and J. W. Bats, Angew. Chem., Int. Ed., 2008, 47, 7539; (k) L. Zu, H. Li, H. Xie, J. Wang, W. Jiang, Y. Tang and W. Wang, Angew. Chem., Int. Ed., 2007, 46, 3732.

24 (a) S. G. Davies, R. L. Sheppard, A. D. Smith and J. E. Thomson, Chem. Commun., 2005, 3802; (b) B. List, L. Hoang and H. J. Martin, Proc. Natl. Acad. Sci. U. S. A., 2004, 101, 5839; (c) Z. G. Hajos and D. R. Parrish, J. Org. Chem., 1974, 39, 1615; (d) U. Eder, G. Sauer and R. Wiechert, Angew. Chem., Int. Ed. Engl., 1971, 10, 496.

25 For examples of organocatalysed synthesis of hydrindane motifs, see: (a) Y. Stöckl, W. Frey, J. Lang, B. Claasen, A. Baro and S. Laschat, Synthesis, 2019, 51, 1123; (b) S. Koshino, E. Kwon and Y. Hayashi, Eur. J. Org. Chem., 2018, 5629; (c) K. S. Halskov, B. S. Donslund, S. Barfüsser and K. A. Jørgensen, Angew. Chem., Int. Ed., 2014, 53, 4137; (d) P. He, X. Liu, J. Shi, L. Lin and X. Feng, Org. Lett., 2011, 13, 936; (e) N. T. Vo, R. D. M. Pace, F. O'Hara and M. J. Gaunt, J. Am. Chem. Soc., 2008, 130, 404; (f) Y. Hayashi, H. Sekizawa, J. Yamaguchi and H. Gotoh, J. Org. Chem., 2007, 72, 6493; (g) Y. Hayashi, H. Gotoh, T. Tamura, H. Yamaguchi, R. Masui and M. Shoji, J. Am. Chem. Soc., 2005, 127, 16028.

26 (a) Y. Hayashi, H. Gotoh, T. Hayashi and M. Shoji, Angew. Chem., Int. Ed., 2005, 44, 4212; (b) M. Marigo, T. C. Wabnitz, D. Fielenbach and K. A. Jørgensen, Angew. Chem., Int. Ed., 2005, 44, 794.

27 (a) F. G. Calvo-Flores, M. J. Monteagudo-Arrebola, J. A. Dobado and J. Isac-García, Top. Curr. Chem., 2018, 376, 18; (b) C. Capello, U. Fischer and K. Hungerbühler, Green Chem., 2007, 9, 927.

28 For recent reviews on flow photoreactors, see: (a) M. Di Filippo, C. Bracken and M. Baumann, Molecules, 2020, 25, 356; (b) T. H. Rehm, ChemPhotoChem, 2019, 3, 1. For a recent comprehensive review of flow chemistry, see: (c) M. B. Plutschack, B. Pieber, K. Gilmore and P. H. Seeberger, Chem. Rev., 2017, 117, 11796. 